\title{
Efektivitas Akupresur dan Minuman Jahe terhadap Pengurangan Intensitas Nyeri Haid/Dismenore Pada Remaja Putri
}

\author{
Indah Dewi Sari*, Utary Dwi Listiarini \\ Jurusan D4 Kebidanan Institut Kesehatan Helvetia, Medan, Indonesia \\ *Correspondence email: indahdewi@helvetia.ac.id, utarydwilistarini@helvetia.ac.id
}

\begin{abstract}
Abstrak. Setengah dari perempuan di Indonesia mengalami nyeri haid/dismenorea sebesar 54,89\%, berbagai gangguan meliputi nyeri abdomen, kram dan sakit pada bagian punggung. Tujuan Penelitian ini untuk Mengetahui efektivitas akupresure, minuman jahe dan perbedaan pemberian dan minuman jahe terhadap penguranagan Intensitas Nyeri haid/Dismenore Pada Remaja Putri di SMK Swasta PAB 5 Tahun 2020. Desain penelitian ini menggunakan quasi eksperimen pre dan posttest dengan sampel 30 mahasiswa yang dibagi dua kelompok. Masing-masing kelompok diberikan Akupresure dan Minuman jahe pada pagi dan sore hari selama menstruasi dari hari pertama sampai hari kedua. Responden dilakukan pengkajian nyeri sebelum dan sesudah diberikan intervensi. Hasil uji normalitas Shapiro-wilk terdapat data Sig $(p<0,05)$. Uji Wilcoxon terdapat nilai $p$-value 0,002 $(p<0,05)$ yang artinya ada efektivitas Akupresure terhadap pegurangan intensitas nyeri haid/dismenore, terdapat nilai $p$-value $0,001(p<0,05)$ artinya ada efektivitas minuman jahe terhadap pegurangan intensitas nyeri haid/dismenore, terdapat nilai $p$-value $0,034(p<0,05)$ artinya ada perbedaan efektivitas Akupresure dan minuman jahe terhadap pegurangan intensitas nyeri haid/dismenore. Ada efektivitas pemberian akupresure, minuman jahe, dan ada perbedaan pemberian akupresure dan minuman jahe terhadap intensitas nyeri haid/Dismenore pada Remaja Putri. Diharapkan kepada pihak sekolah untuk menyediakan minuman jahe dan tindakan Akupresure kepada remaja putri yang mengalami nyeri haid/dismenore sehingga bisa mengikuti kegiatan belajar disekolah.
\end{abstract}

Kata Kunci: Akupresure; Dismenore Minuman Jahe; Remaja Putri

Abstract. Half of the women in Indonesia experience menstrual pain / dysmenorrhoea, 54.89\%, experience various disorders including abdominal pain, cramps and back pain. The purpose of this study was to determine the effectiveness of acupressure, ginger drink and the difference in giving acupressure and ginger drink to reducing the intensity of menstrual pain / dysmenorrhea in young women at SMK Swasta PAB 5 Klambir Lima 2020. The design of this study used a quasi-experimental pre and post test with a sample of 30 students who were divided into two groups. Each group was given acupressure and ginger drink in the morning and evening during menstruation from day one to day two. Respondents were assessed for pain before and after the intervention was given. The results of the Shapiro-Wilk normality test contained Sig data $(p<0.05)$. The Wilcoxon test has a $p$ value of $0.002(p<0.05)$, which means that acupressure is effective in reducing the intensity of menstrual pain / dysmenorrhea, there is a p-value of $0.001(p<0.05)$ which means that ginger is effective against reducing pain intensity. menstruation $/$ dysmenorrhea, there is a p-value of $0.034(p<0.05)$, which means that there is a difference in the effectiveness of acupressure and ginger drink in reducing the intensity of menstrual pain / dysmenorrhea. There is an effectiveness of giving acupressure, ginger drink, and there is a difference in giving acupressure and ginger drink on the intensity of menstrual pain / dysmenorrhea on young women. It is hoped that the school will provide ginger drinks and acupressure measures to young women who experience menstrual pain / dysmenorrhea so that they can participate in learning activities at school.

Keywords: Acupressure; Dysmenorrhea; Ginger Drink; Young Women

\section{PENDAHULUAN}

Berdasarkan angka kejadian nyeri haid di Indonesia yaitu $54,89 \%$, setengah dari wanita di Indonesia mengalami nyeri haid/ dismenorea, dari berbagai gangguan yang terjadi pada perempuan saat menstruasi mereka juga disisi lain harus beraktifitas sama seperti perempuan yang tidak sedang mengalami menstruasi. (Heni Setyowati, 2018)

Upaya dalam menangani nyeri haid (dismenorea) dapat dilakukan secara. nonfarmakologis untuk membantu mengurangi nyeri haid diantaranya dengan sejumlah rempah-rempah, kompres hangat pada punggung, perut bagian bawah, mandi air hangat, melakukan pemijatan olahraga, aroma terapi, mendengarkan musik, membaca buku atau menonton film dapat menolong. (Suparmi, 2017)
Akupresur, yaitu tindakan fisioterapi dengan memberikan pemijatan dan stimulasi pada titik-titik tertentu pada tubuh (garis aliran energi atau meridian) untuk menurunkan nyeri haid dan terbukti bermanfaat untuk pencegahan penyakit (Heni Setyowati, 2018)

Sesuai dengan hasil penelitian yang dilakukan oleh menunjukkan bahwa pemberian terapi akupresur efektif menurunkan intensitas nyeri pada remaja putri dengan dysmenorrhea primer di SMK Muhammadiyah 02 Pekanbaru sebesar 0,615 poin dan kualitas nyeri 0,577 poin dengan nilai $p(\alpha<0,05)$. Penelitian yang lain mengatakan bahwa, terapi akupresur dapat menurunkan intensitas nyeri dysmenorrhea 2,73 poin lebih besar dibandingkan dengan responden yang tidak mendapat terapi akupresur sebesar 0.07 poin. (Hasanah, 2014) 
Penanganan yang lain seperti terapi ramuan herbal dapat dilakukan dengan cara menggunakan obat tradisional yang berasal dari bahan-bahan tanaman. Beberapa bahan tanaman dipercaya dapat mengurangi rasa nyeri. Salah satu tanaman tersebut adalah jahe (Zingibers Officinale Rosc.) yang bagian rimpangnya berfungsi sebagai analgesik, antipiretik, dan anti inflamasi. (Suparmi, 2017)

Pemberian ekstrak jahe merah efektif dapat menurunkan dismenore. Dengan demikian ekstrak jahe merah dapat menjadi salah satu alternatif pengobatan non farmakologi dalam penanganan nyeri dismenore. Hasil penelitian menunjukkan bahwa intensitas nyeri sebelum intervensi hampir seluruh responden dengan nyeri berat dan sesudah intervensi hampir seluruhnya dengan nyeri sedang. Hasil analisa didapatkan ada perbedaan antara intensitas nyeri sebelum intervensi dengan sesudah intervensi ( $p$ value 0,000). (Rahayu dan Nujulah, 2018)

Survey awal yang dilakukan di SMK Swasta PAB 5 Klambir Lima pada tanggal 20 Februari 2010 dari Data Usaha Kesehatan Sekolah (UKS), bahwa setiap bulan selalu ada Remaja putri yang masuk UKS dengan alasan mengalami nyeri haid. Kemudian peneliti melakukan wawancara terhadap 10 remaja putri di SMK Swasta PAB 5 Klambir Lima didapatkan 7 remaja putri mengalami dismenorea. Responden melakukan penanganan nyeri haid dengan menggunakan minyak kayu putih, istirahat di tempat tidur, minum air hangat, minum obat anti nyeri, kompres air hangat di bagian perut dan ada yang tidak melakukan apa-apa karena terkadang tidak ada obat untuk nyeri dan ada remaja putri yang tidak bisa mengkonsumsi obat obatan disekolah,.

Berdasarkan latar belakang tersebut, maka peneliti tertarik untuk melakukan penelitian tentang "Pengaruh Konsumsi Ramuan Jahe Untuk Meredakan Nyeri Haid Pada Remaja di SMK Swasta PAB 5 Klambir Lima, Kecamatan Hamparan Perak, Kabupaten Deli Serdang.

\section{METODE \\ Desain Penelitian}

Desain penelitian yang dingunakan adalah Quasi Eksperiment Design. Penelitian ini akan membandigkan kedua kelompok eksperimen yang akan diberikan test berupa pretest dan posttest. Responden di bagi menjadi dua kelompok yaitu kelompok 1 sebanyak 15 Responden diberikan Tindakan Akupresure dan kelompok 2 sebanyak 15 Responden diberikan rebusan jahe. Masingmasing kelompok diberikan Akupresure dan Minuman jahe pada pagi dan sore hari selama menstruasi dari hari pertama sampai hari kedua.

\section{Lokasi Penelitian}

Lokasi penelitian dilakukan di SMK PAB 5 Klambir Lima Kecamatan Hamparan Perak Kabupaten Deli Serdang Kecamatan Hamparan Perak Tahun 2020.

\section{Populasi dan Sampel}

Populasi dan sampel dalam penelitian ini adalah Remaja Putri SMK Swasta PAB 5 Klmabir Lima. Kec. Hamparan Perak, Kabupaten Deli Serdang. Teknik sampling dengan menggunakan tekhnik purposive sampling yaitu 30 remaja putri yang sesuai dengan kriteria inklusi. Responden di bagi menjadi dua kelompok yaitu kelompok 1 dengan tindakan Akupresure dan 1 kelompok dengam minum jahe. Masing-masing kelompok sebanyak 15 remaja putri.

\section{Metode Pengumpulan Data}

Metode Pengumpulan data diperolah dari data primer, data sekunder dan data tertier.

\section{Analisis Data}

Analisa data pada penelitian ini menggunakan analisis univariat : Tujuanya untuk menjelaskan distribusi frekwensi dari masing-masing variabel independen dan variabel dependen, kemudaian menggunakan analisis bivariat, data yang diperoleh dari instrumen penelitian diolah dan dianalisis dengan menggunakan statistik yaitu Uji- $T$. Hasi pada penelitian ini menggunakan Uji-Wilxocon

\section{HASIL DAN PENELITIAN Analisis Univariat}

Tabel 1. Distribusi Responden Sebelum Diberikan Akupresure

\begin{tabular}{llll}
\hline No & Rentang Nyeri & F & \% \\
\hline 1 & Nyeri Ringan & 3 & 20.0 \\
2 & Nyeri Sedang & 9 & 60.0 \\
3 & Nyeri Berat & 3 & 20.0 \\
& Total & 15 & 100 \\
\hline
\end{tabular}

Berdasarkan tabel 1. Hasil pengukuran menunjukkan bahwa sebelum diberikan Akupresure 20\% mengalami nyeri ringan, $60 \%$ responden mengalami nyeri sedang dan $20 \%$ mengalami nyeri berat

Tabel 2. Distribusi Responden Setelah Diberikan Akupresure

\begin{tabular}{llll}
\hline No & Rentang Nyeri & F & \% \\
\hline 1 & Tidak Nyeri & 3 & 20.0 \\
2 & Nyeri Ringan & 9 & 60.0 \\
3 & Nyeri Sedang & 3 & 20.0 \\
& Total & 15 & 100 \\
\hline
\end{tabular}

Berdasarkan tabel 2 Hasil pengukuran menunjukkan bahwa setelah diberikan Akupresure 20\% tidak nyeri, $60 \%$ responden mengalami nyeri Ringan dan $20 \%$ mengalami nyeri sedang. 
Indah Dewi Sari dan Utari Dwi Listiarini, Efektivitas Akupresur dan Minuman Jahe terhadap Pengurangan Intensitas Nyeri Haid/Dismenore Pada Remaja Putri

Tabel 3. Distribusi Responden Sebelum diberikan Minuman Jahe

\begin{tabular}{llll}
\hline No & Rentang Nyeri & F & \% \\
\hline 1 & Nyeri Ringan & 2 & 13,3 \\
2 & Nyeri Sedang & 10 & 66.7 \\
3 & Nyeri Berat & 3 & 20.0 \\
& Total & 15 & 100 \\
\hline
\end{tabular}

Berdasarkan tabel 3 Hasil pengukuran menunjukkan bahwa sebelum diberikan minuman jaeh $13,3 \%$ nyeri ringan, $66,7 \%$ responden mengalami nyeri sedang dan $20 \%$ mengalami nyeri berat.

Tabel 4. Distribusi Responden Setelah diberikan Rebusan

\begin{tabular}{lllc}
\multicolumn{5}{c}{ Jahe } \\
\hline No & Rentang Nyeri & F & \% \\
\hline 1 & Tidak Nyeri & 7 & 46,7 \\
2 & Nyeri Ringan & 7 & 46.7 \\
3 & Nyeri Sedang & 1 & 6.7 \\
& Total & 15 & 100 \\
\hline
\end{tabular}

Berdasarkan tabel 4. Hasil pengukuran menunjukkan bahwa setelah diberikan rebusan jahe 46.6 $\%$ tidak nyeri, $46,7 \%$ responden mengalami nyeri sedang dan $6,7 \%$ mengalami nyeri berat.

Tabel 5. Distribusi frekuensi Efektivitas pemberian

Akupresure terhadap pengurangan intensitas nyeri haid/Dismenore pada Remaja Putri di SMK Swasta PAB 5 Klambir Lima Tahun 2020

Test Statistics $^{\mathrm{b}}$

sesudah diberikan - sebelum diberikan Intervensi Akupresure

\begin{tabular}{ll}
$\mathrm{Z}$ & $-3.035^{\mathrm{a}}$ \\
Asymp. Sig. (2- tailed) & .002 \\
\hline
\end{tabular}

a. Based on positive ranks.

b. Wilcoxon Signed Ranks Test

Berdasarkan Tabel 5 pada Uji Wilcoxon dapat dilihat bahwa tabel diatas didapatkan nilai $p=0,002$, maka disimpulkan bahwa Ada Efektivitas Akupresure Terhadap Pengurangan intensitas nyeri haid/Dismenore pada Remaja Putri di SMK Swasta PAB 5 Klambir Lima Tahun 2020.

Tabel 6. Distribusi frekuensi Efektivitas pemberian Munuman Jahe terhadap pengurangan intensitas nyeri haid/Dismenore pada Remaja Putri di SMK Swasta PAB 5 Klambir Lima Tahun 2020

sesudah diberikan - sebelum diberikan Intervensi Minuman Jahe
Z
$-3.397^{\mathrm{a}}$

Asymp. Sig. (2-tailed) .001

a. Based on positive ranks.

b. Wilcoxon Signed Ranks Test

Berdasarkan Tabel 6 pada Uji Wilcoxon dapat dilihat bahwa tabel diatas didapatkan nilai $p=0,001$, maka disimpulkan bahwa Ada Efektivitas Minuman Jahe Terhadap Pengurangan intensitas nyeri haid/Dismenore pada Remaja Putri di SMK Swasta PAB 5 Klambir Lima Tahun 2020.

Tabel 7. Distribusi frekuensi Perbedaan Efektivitas

Akupresure dan pemberian Munuman Jahe terhadap pengurangan intensitas nyeri haid/Dismenore pada Remaja

Putri di SMK Swasta PAB 5 Klambir Lima Tahun 2020.

Test Statistics ${ }^{b}$

Setelah diberikan Jahe - Setelah diberikan Akupresure

$\mathrm{Z} \quad-2.121^{\mathrm{a}}$

Asymp. Sig. (2-tailed) .034

a. Based on positive ranks.

b. Wilcoxon Signed Ranks Test

Berdasarkan Tabel 7 pada Uji Wilcoxon dapat dilihat bahwa tabel diatas didapatkan nilai $p=0,034$, maka dapat disimpulkan bahwa ada Perbedaan Efektivitas pemberian Akupresure dan

Minuman Jahe Terhadap pengurangan intensitas nyeri haid/Dismenore pada Remaja Putri di SMK Swasta PAB 5 Klambir Lima Tahun 2020.

\section{Pembahasan}

Distribusi frekuensi Efektivitas pemberian Akupresure terhadap pengurangan intensitas nyeri haid/Dismenore pada Remaja Putri di SMK Swasta PAB 5 Klambir Lima Tahun 2020

Berdasarkan Tabel 5 pada Uji Wilcoxon dapat dilihat didapatkan nilai $p=0,002$, maka disimpulkan bahwa Ada Efektivitas Akupresure Terhadap Pengurangan intensitas nyeri haid/Dismenore pada Remaja Putri di SMK Swasta PAB 5 Klambir Lima Tahun 2020

Akupresur salah satu bentuk fisioterapi dengan memberikan pemijatan dan stimulasi pada titik-titik tertentu pada tubuh (garis aliran energi atau meridian) untuk menurunkan nyeri dan terbukti bermanfaat untuk pencegahan penyakit (Heni Setyowati, 2018)

Pemberian terapi akupresur efektif menurunkan intensitas nyeri pada remaja putri dengan dysmenorhea primer di SMK Muhammadiyah 02 Pekanbaru sebesar 0,615 poin dan kualitas nyeri 0,577 poin dengan nilai $\mathrm{p}$ $(\alpha<0,05)$. Penelitian yang lain mengatakan bahwa, terapi akupresur dapat menurunkan intensitas nyeri dysmenorrhea 2,73 poin lebih besar dibandingkan dengan responden yang tidak mendapat terapi akupresur sebesar 0.07 poin. (Hasanah, 2014)

Akupresur adalah pengobatan cina yang sudah dikenal sejak ribuan tahun lalu dan dengan memberikan tekanan atau pemijatan dan menstimulasi titik-titik tertentu dalam tubuh. Pada dasarnya terapi akupresur merupakan pengembangan dari teknik akupuntur, tetapi media yang digunakan bukan jarum, tetapi jari tangan atau benda tumpul. Tujuannya untuk merangsang kemampuan alami menyembuhkan diri sendiri dengan cara mengembalikan keseimbangan energi positif tubuh. (Fengge, 2012) 
Berdasarkan hasil analisa perubahan skala nyeri haid pada kelompok perlakuan dan kelompok kontrol, menggunakan uji independent sample t-test, menghasilkan nilai t sebesar 19,138 yang menunjukkan bahwa terdapat perubahan, antara perubahan skala nyeri dismenore kelompok kontrol dengan kelompok perlakuan. Hasil analisa lebih lanjutdiperoleh nilai Sig. 2-tailed sebesar $0.000(p<0,05)$, yang berarti bahwa terdapat perbedaan yang signifikan antara perubahan skala nyeri dismenore pada kelompok perlakuan dan kelompok kontrol. (Efriyanthi et al, 2015)

Hasil penelitian menunjukkan nyeri haid responden setelah intervensi berupa akupresur dengen teknik tuina diperoleh adanya perubahan nyeri haid berkurang, dengan hasil analisa signifikan yaitu nilai $\mathrm{p}$ $=0,000$. Akupresur salah satu bentuk fisioterapi dengan memberikan pemijatan dan stimulasi tertentu di titik-titik akupoin pada tubuh disebut meridian atau garis aliran energi sebagai penurunan nyeri haid. Teknik ini dapat diimplementasikan ke dalam asuhan kebidanan komplementer sebagai pengurangan nyeri haid (disminore) pada remaja putri. (Fitria $\mathrm{F}$ dan Haqqattiba'ah, 2020)

Menurut peneliti selama melakukan penelitian dengan Akupresure kepada remaja putri dengan menekan lokasi pemijatan pada lokasi yang letaknya 4 jari diatas mata kaki bagian dalam, lokasi pijatan ditekan selama 30 hitungan Lokasi yang terletak dipunggung tangan pada tonjolan tertinggi, ibu jari dan telunjuk dirapatkan, lokasi pijatan ditekan selama 30 hitungan dan Lokasi yang terletak 4 jari dibawah tempurung lutut ditepi luar tulang kering, Lokasi pijatan ditekan selama 30 hitungan. Akupresure dilakukan selama 2 hari dan menunggu hasil intensitas nyeri sampai 30 menit, Responden merasakan rileks dan berkurang rasa nyeri haid pada perut yang berasal dari kram rahim yang terjadi selama menstruasi dan sebagian responden yang tidak bisa melakukan aktifitas bisa kembali beraktifitas.

\section{Distribusi frekuensi Efektivitas pemberian Munuman Jahe terhadap pengurangan intensitas nyeri haid/Dismenore pada Remaja Putri di SMK Swasta PAB 5 Klambir Lima Tahun 2020.}

Berdasarkan Tabel 6 pada Uji Wilcoxon dapat dilihat bahwa tabel diatas didapatkan nilai $p=0,001$, maka disimpulkan bahwa Ada Efektivitas Minuman Jahe Terhadap Pengurangan intensitas nyeri haid/Dismenore pada Remaja Putri di SMK Swasta PAB 5 Klambir Lima Tahun 2020.

Jahe adalah tanaman rimpang yang sangat populer sebagai rempah-rempah dan bahan obat . Zat besi yang terkandung pada jahe dapat mencegah anemia saat haid. Kalsium dan vitamin $\mathrm{C}$ berguna untuk menegangkan saraf dan mengurangi rasa nyeri. Minuman jahe ini bisa membuat tubuh rileks dan pikiran menjadi fresh. (Ediati sasmito, 2017)
Jahe merah memiliki kandungan minyak atsiri yang cukup tinggi dan kandungan kimia gingerol dalam jahe merah mampu memblokir prostaglandin sehingga dapat menurunkan nyeri pada saat menstruasi. Dari beberapa uji analisis pengaruh jahe terhadap menstruasi ditemukan adanya pengaruh jahe terhadap tingkat nyeri saat menstruasi karena jahe (ginger) sama efektifnya dengan asam mefenamat (mefenamic acid) dan ibuprofen untuk mengurangi nyeri pada wanita dengan nyeri haid. (Pratiwi dan Mutiara, 2017)

Pemberian ekstrak jahe merah efektif dapat menurunkan dismenore. Dengan demikian ekstrak jahe merah dapat menjadi salah satu alternatif pengobatan non farmakologi dalam penanganan nyeri dismenore. Hasil penelitian menunjukkan bahwa intensitas nyeri sebelum intervensi hampir seluruh responden dengan nyeri berat dan sesudah intervensi hampir seluruhnya dengan nyeri sedang. Hasil analisa didapatkan ada perbedaan antara intensitas nyeri sebelum intervensi dengan sesudah intervensi ( $p$ value 0,000). ( Rahayu dan Nujulah, 2018)

Hasil penelitian lain tentang Rebusan Buah Asam Dan Jahe Sebagai Upaya Mengurangi Dismenor dianalisis dengan menggunakan independent $\mathrm{T}$-Test. Hasil didapatkan responden yang diberikan rebusan buah asam sebelum intervensi $60 \%$ mengalami nyeri sedang dan setelah intervensi $87 \%$ mengalami nyeri ringan, sedangkan responden yang diberikan rebusan jahe sebelum intervensi $67 \%$ mengalami nyeri sedang dan setelah intervensi $73 \%$ mengalami nyeri ringan sehingga disimpulkan rebusan jahe lebih efektif dibandingkan rebusan asam untuk mengurangi dismenore. (Gustin, 2019)

Selama penelitian dengan melakukan pemberian minuman Jahe merah 15 gram ditambah gula merah 10 gram dan air sebanyak $400 \mathrm{ml}$, kemudian direbus sampai tersisa $200 \mathrm{ml}$ dan dimunum 2 kali sehari pada hari pertama dan kedua haid saat mengalami nyeri haid. Responden merasakan berkurangnya nyeri haid yang dialami nya, responden juga mengatakan lebih rilek dan dapat melakukan aktivitas kembali

Kandungan jahe yang mengandung gingerol yang mampu memblokir prostaglandin.. Selain itu tidak ada efek samping jahe. Jahe memiliki efektivitas yang sama dengan ibuprofen dalam mengurangi nyeri. Cara kerja ibuprofen dikenal sangat cepat dan efektif diserap setelah pemberian peroral. Tingkat konsentrasi di dalam plasma sangat singkat yaitu antara 15 menit-1 jam. Kerja dari ibuprofen sama dengan jahe yaitu dengan menghambat sintesis prostaglandin. Obat-obat atau herbal yang sejenis dengan ibuprofen sangat mudah diabsorbsi oleh sistem gastrointestinal. (Corwin EJ) 
Indah Dewi Sari dan Utari Dwi Listiarini, Efektivitas Akupresur dan Minuman Jahe terhadap Pengurangan Intensitas Nyeri Haid/Dismenore Pada Remaja Putri

Distribusi frekuensi Perbedaan Efektivitas Akupresure dan pemberian Minuman Jahe terhadap pengurangan intensitas nyeri haid/Dismenore pada Remaja Putri di SMK Swasta PAB 5 Klambir Lima Tahun 2020.

Berdasarkan Tabel 7 pada Uji Wilcoxon dapat dilihat bahwa tabel diatas didapatkan nilai $p=0,034$, maka dapat disimpulkan bahwa ada Perbedaan Efektivitas pemberian Akupresure dan Minuman Jahe Terhadap pengurangan intensitas nyeri haid/Dismenore pada Remaja Putri di SMK Swasta PAB 5 Klambir Lima Tahun 2020.

Hasil penelitian diatas menunjukan perbedaan pemberian jahe lebih efektiv dibandingkan pemberian Akupresure. Efektivitas sebelum diberikan minuman jahe $13.3 \%$ mengalami nyeri ringan $13,3 \%$, nyeri sedang $66,7 \%$ dan Nyeri Berat 3\%, sesudah minum jahe tidak nyeri $46 \%$, nyeri ringan $46 \%$ dan Nyeri sedang 6,7\%. Sedangkan sebelum diberikan Akupresure nyeri ringan $20 \%$, nyeri sedang $60 \%$ dan nyeri berat $20 \%$, sesudah akupresure mengalami tidak nyeri $3 \%$, nyeri ringan $60 \%$ dan nyeri sedang $3 \%$.

Pemberian minuman jahe lebih efetiv dibanding akupresure karena Tingkat konsentrasi di dalam plasma sangat singkat yaitu antara 15 menit-1 jam . pasien lebih merasakan perutnya hangat sehingga cepat mengurangi nyeri haid.

Kandungan jahe yang mengandung gingerol yang mampu memblokir prostaglandin. Selain itu tidak ada efek samping jahe. Jahe memiliki efektivitas yang sama dengan ibuprofen dalam mengurangi nyeri. Cara kerja ibuprofen dikenal sangat cepat dan efektif diserap setelah pemberian peroral.. Kerja dari ibuprofen sama dengan jahe yaitu dengan menghambat sintesis prostaglandin. Obat-obat atau herbal yang sejenis dengan ibuprofen sangat mudah diabsorbsi oleh sistem gastrointestinal. (Corwin EJ)

Remaja yang mengalami haid, mengalami nyeri dengan tingkat dan sifat yang berbeda-beda mulai dari yang ringan hingga yang berat, meliputi nyeri abdomen, kram dan sakit pada bagian punggung. (Desta Ayu Cahaya Rosyida, 2019)

Upaya dalam menangani nyeri haid diantaranya dengan sejumlah rempah-rempah, kompres hangat pada punggung, perut bagian bawah, mandi air hangat, melakukan pemijatan. (Suparmi, 2017)

Terapi akupresur efektif menurunkan intensitas nyeri pada remaja putri dengan dysmenorrhea primer di SMK Muhammadiyah 02 Pekanbaru sebesar 0,615 poin dan kualitas nyeri 0,577 poin dengan nilai $p(\alpha<0,05)$. Penelitian yang lain mengatakan bahwa, terapi akupresur dapat menurunkan intensitas nyeri dysmenorrhea 2,73 poin lebih besar dibandingkan dengan responden yang tidak mendapat terapi akupresur sebesar 0.07 poin. (Hasanah, 2014)

Berdasarkan penelitian yang dilakukan yang berjudul Pengaruh ekstrak jahe merah terhadap penurunan disminore pada remaja di Panti Asuhan di
Surakarta mengatakan bahwa, Terjadi penurunan skala nyeri sesudah diberikan ekstrak jahe merah pada kelompok perlakuan pada hari ke-1 sampai ke-3 $(\mathrm{p}=0,000<0,05)$ sedangkan pada kelompok kontrol tidak mengalami penurunan secara signifikan (hari ke 1-3 $\mathrm{p}=1,00>0,05)$. Pemberian ekstrak jahe merah selama 5 hari efektif terhadap penurunan skala nyeri pada dismenorea pada remaja di Panti Asuhan Putri di Surakarta. (Suparmi, 2017)

\section{SIMPULAN}

Kesimpulan pada penelitian ini adalah Ada Efektivitas Akupresure Terhadap Pengurangan intensitas nyeri haid/Dismenore pada Remaja Putri, Ada Efektivitas Minuman Jahe Terhadap Pengurangan intensitas nyeri haid/Dismenore pada Remaja Putri dan ada Perbedaan Efektivitas pemberian Akupresure dan Minuman Jahe Terhadap pengurangan intensitas nyeri haid/Dismenore pada Remaja Putri di SMK Swasta PAB 5 Klambir Lima Tahun 2020.

Sebagai bahan masukan pihak sekolah untuk menyediakan obat non farmakologi salah satunya yaitu minuman jahe dan mampu melakukan tindakan pemijitan Akupresure untuk membantu siswa yang mengalami nyeri haid sehingga dapat mengikuti kegiatan belajar disekolah.

\section{DAFTAR PUSTAKA}

Corwin EJ. Buku Saku Patofisiologi

Desta Ayu Cahaya Rosyida, SST. MTK. Buku Ajar Kesehatan Reproduksi Remaja dan Wanita.pdf. 2019. p. 144.

Efriyanthi S, Suardana IW, Suari W. Pengaruh Terapi Akupresur Sanyinjiao Point Terhadap Intensitas Nyeri Dismenore Primer Pada Mahasiswi Semester Viii Program Studi Ilmu Keperawatan. Coping Community Publ Nurs. 2015;3(2).

Fengge A. Terapi akupresur manfaat dan teknik pengobatan. Yogyakarta Crop Circ Corp. 2012;

Fitria F, Haqqattiba'ah A. Pengaruh Akupresur dengan Teknik Tuina terhadap Pengurangan Nyeri Haid (Disminore) pada Remaja Putri. J Ners dan Kebidanan (Journal Ners Midwifery). 2020;7(1):73-81.

Gustin T. Rebusan Buah Asam dan Jahe Sebagai Upaya Mengurangi Dismenore. Faletehan Heal J. 2019;6(1):11-5.

Heni Setyowati ER. Akupresur untuk kesehatan wanita berbasis hasil penelitian. 2018 .

Hasanah O. Efektifitas Akupresur terhadap Dismenore pada Remaja Putri. Riau University; 2014.

Prof. Dr. Ediati sasmito. Immunodulator Bahan Alami. Yogyakarta: Rapha Publishing; 2017.

Pratiwi LA, Mutiara H. Pengaruh Jahe terhadap Nyeri saat Menstruasi. Majority. 2017;6(1):51-4.

Rahayu KD, Nujulah L. Efektifitas Pemberian Ekstrak Jahe Terhadap Intensitas Dismenore Pada 
Indah Dewi Sari dan Utari Dwi Listiarini, Efektivitas Akupresur dan Minuman Jahe terhadap Pengurangan Intensitas Nyeri Haid/Dismenore Pada Remaja Putri

Mahasiswi Akademi Kebidanan Sakinah

Pasuruan. EMBRIO. 2018;10(2):70-5.

Suparmi, Musriyati N. Effects Of Ginger Extract (Zingiber Officinale Var Rubrum Rhizoma Zingi) On Dismenore Decrease In Adolescentin Panti Asuhan In Surakarta. 2017;4(November):65-72. 